\title{
DESIGN AND CONSTRUCTION OF SEPTUM MAGNETS AT THE 7-GeV APS*
}

\author{
A. Gorski," R. Wright, C. Pitts, S. Sharma \\ Advanced Photon Source, Argonne National Laboratory, 9700 S. Cass Avenue, Argonne, IL 60439
}

\section{Abstract}

The mechanical design, construction, and assembly procedure of six different septum magnet designs used in the Advanced Photon Source (APS) facility will be described. This will include a positron accumulator ring (PAR) AC septum magnet, a synchrotron thin injection septum, AC thin and thick extraction septa, and storage ring $\mathrm{AC}$ thick and thin injection septum magnets.

Design parameters, material selection, assembly procedures, and operational results will be presented.

\section{INTRODUCTION}

The development of septum magnet fabrication at the APS facility has been a challenging endeavor. Pulsed septum magnet design and construction offers the magnet engineer several challenges in material selection, magnet assembly, and construction tolerances. Nonsteady-state forces can lead to material flexture and resultant metal fatigue. High radiation environments limit material selection for coil electrical insulating materials. In some situations, designs require that the laminated core of the magnet be in the vacuum environment. Outgassing of trapped interlamination air can be a major concern when one is required to maintain an ultrahigh vacuum. With core-in-vacuum designs special care must be taken with water connections. No water to vacuum joints are allowed in the septum magnet design. The electrical constraints are no less trivial. Pulsed septum magnets naturally imply high currents of the order of 500 to 12000 amps.

The most important feature of septum magnets is to have a homogeneous field in the magnet gap and a low to zero leakage field outside the gap such that the circulating beam is not affected. A single septum conductor is used to separate the gap field from the zero field external region. To facilitate merging of the injected and stored beams, the septum conductor is designed to be as thin as possible without compromising its mechanical, thermal, electrical, or magnetic shielding performance. In some designs, septum conductors can be $2.5 \mathrm{~mm}$ thick or less.

\footnotetext{
Work supported by the U.S. Department of Energy, Office of Basic Energy Sciences, under Contract No. W-31-109-ENG-38.

'Email: gorski@aps.anl.gov
}

\section{MECHANICAL AND OPERATIONAL PARAMETERS}

The APS facility uses six different septum magnets that are described below.

\subsection{PAR AC Injection and Extraction Septum}

The PAR AC septum magnet is mechanically the most complex of all the APS septa. Designed to operate with a peak current of $12.057 \mathrm{kA}$ and a repetition rate of $60 \mathrm{~Hz}$, its thermal design required considerable development. The complete magnet is contained in a vacuum enclosure $61 \mathrm{~cm}$ long by $25.4 \mathrm{~cm}$ wide by $17.8 \mathrm{~cm}$ high. The core, septum plate, and backleg conductor are all water cooled. The septum plate thickness is $2 \mathrm{~mm}$. The core is stacked laminations of M22 silicon steel with C5 coating on both sides; each lamination thickness is $0.36 \mathrm{~mm}$. The core end-pack is fabricated from laminations that are modified with tapered bevels designed to reduce heating at the ends. Additional cooling plates are provided on the end packs for water cooling. All power and cooling water feedthroughs are electrically insulated from the vacuumen enclosure. The magnet is shown schematically in 0 . with operational parameters listed in Table 1.

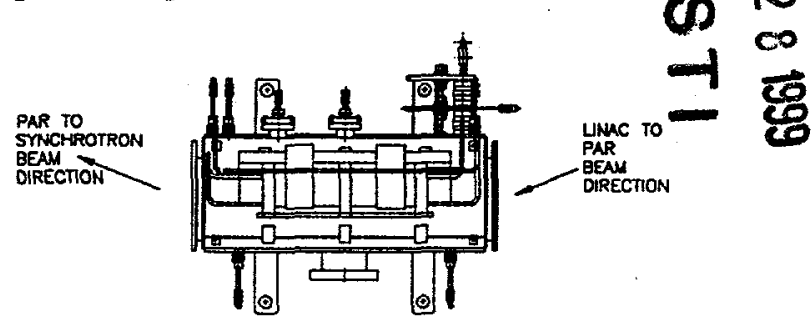

Figure 1. PAR AC septum magnet

Table 1: PAR AC septum magnet parameters

\begin{tabular}{|l|l|}
\hline Number & 1 \\
\hline Physical Length & $0.48 \mathrm{~m}$ \\
\hline Effective Length & $0.4 \mathrm{~m}$ \\
\hline Field Strength & $0.75 \mathrm{~T}$ \\
\hline Maximum Septum Thickness & $2 \mathrm{~mm}(+)$ \\
\hline Magnetic Field Aperture & $7.0 \times 2.0 \mathrm{~cm}$ \\
\hline Bending Angle & $199.6 \mathrm{mrad}$ \\
\hline Peak Current & $12.057 \mathrm{kA}$ \\
\hline Peak Power & $29 \mathrm{~kW}$ \\
\hline Rep Rate & $60 \mathrm{pps}$ \\
\hline Pulse Length (half sine wave) & $275 \mu \mathrm{s}$ \\
\hline Average Power & $0.574 \mathrm{~kW}$ \\
\hline
\end{tabular}




\section{DISCLAIMER}

This report was prepared as an account of work sponsored by an agency of the United States Government. Neither the United States Government nor any agency thereof, nor any of their employees, make any warranty, express or implied, or assumes any legal liability or responsibility for the accuracy, completeness, or usefuiness of any information, apparatus, product, or process disclosed, or represents that its use would not infringe privately owned rights. Reference herein to any specific commercial product, process, or service by trade name, trademark, manufacturer, or otherwise does not necessarily constitute or imply its endorsement, recommendation, or favoring by the United States Government or any agency thereof. The views and opinions of authors expressed herein do not necessarily state or reflect those of the United States Government or any agency thereof. 


\section{DISCLAIMER}

Portions of this document may be illegible in electronic image products. Images are produced from the best available original document. 


\subsection{Synchrotron Injection Thin Septum}

The synchrotron injection thin septum magnet is of the core-in-vacuum design. The core is stacked to a radius of curvature of $3.18 \mathrm{~m}$. The laminations are $0.36-\mathrm{mm}$-thick M22 silicon steel coated with a C5 type insulation on both sides. The laminations are oven baked before use to insure cleanliness. As is usual in the stacking process, the laminations are stacked in approximately $25.4 \mathrm{~mm}$ packs, alternating the witness notches from one side to another. The ends of the stack have solid end packs $1.19 \mathrm{~cm}$ thick, composed of CRS-1018 steel. As can be seen in Fig. 2, all the magnet components are put into a vacuum-tight box-like structure. The septum plate itself is $2 \mathrm{~mm}$ thick and machined from explosion-bonded copper and steel material. It is not direct-driven but rather acts as an eddycurrent shield preventing field from leaking into the field free region. The single-turn primary coil is fabricated from OFHC copper of dimensions $1.59 \mathrm{~cm}$ by $0.635 \mathrm{~cm}$. The synchrotron injection thin septum is shown schematically in Fig. 2 with operational parameters given in Table 2.

At the present time, another synchrotron injection thin septum magnet of an out-of-vacuum core design is being assembled. With core laminations outside the vacuum envelope, this design will allow quick pump down in case of a vacuum leak.

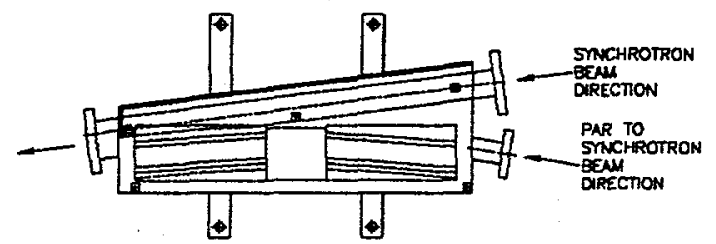

Figure 2: Synchrotron injection thin septum

Table 2: Synchrotron injection thin septum parameters

\begin{tabular}{|l|l|}
\hline Number & 1 \\
\hline Maximum Allowable Septum Thickness & $4 \mathrm{~mm}$ \\
\hline Physical Length & $0.9 \mathrm{~m}$ \\
\hline Effective Length & $0.85 \mathrm{~m}$ \\
\hline Bending Angle & $0.2771 \mathrm{rad}$ \\
\hline Peak Field at 450 MeV & $0.49 \mathrm{~T}$ \\
\hline Gap Height & $30 \mathrm{~mm}$ \\
\hline Gap Width & $40 \mathrm{~mm}$ \\
\hline Peak Current & $11.8 \mathrm{kA}$ \\
\hline Peak Power & $30 \mathrm{kA}$ \\
\hline Pulse Width & $333 \mu \mathrm{s}$ \\
\hline Average Power & $0.02 \mathrm{~kW}$ \\
\hline
\end{tabular}

\subsection{Synchrotron AC Thin Extraction Septum}

This septum magnet is of the core-in-vacuum type with a total septum plate thickness of $4 \mathrm{~mm}$. The core itself is composed of a stack of approximately 2680 laminations ( $0.36 \mathrm{~mm}$ thick) stacked to a core length of $1.03 \mathrm{~m}$. The laminations are a low carbon silicon steel coated with C5 insulation on each side. The ends of the core have solid end packs of CRS-1018 steel, $1.19 \mathrm{~cm}$ thick. The core was stacked and welded in the same fixture alternating 2.54-cm packs of laminations along the length of the core.

The septum plate itself is fabricated from explosionbonded copper and steel plate. The total septum plate thickness is $3.76 \mathrm{~mm}$ and again acts as an eddy-current shield. The septum magnet is shown schematically in Fig. 3. Some operational parameters are given in Table 3.

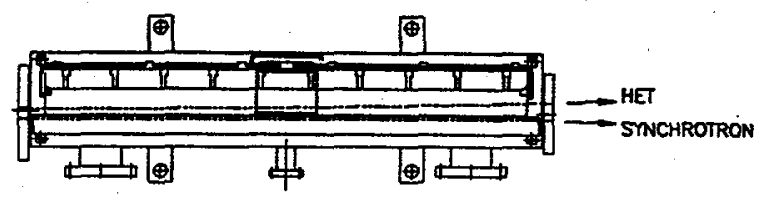

Figure 3: Top view synchrotron extraction AC thin septum

Table 3: Synchrotron AC thin extraction septum parameters

\begin{tabular}{|l|l|}
\hline Number & 1 \\
\hline Maximum Effective Septum Thickness & $4 \mathrm{~mm}$ \\
\hline Physical Length & $1.06 \mathrm{~m}$ \\
\hline Effective Length & $1.05 \mathrm{~m}$ \\
\hline Bending Angle & $33 \mathrm{mrad}$ \\
\hline Peak Field at 7 GeV & $0.73 \mathrm{~T}$ \\
\hline Gap Height & $20 \mathrm{~mm}$ \\
\hline Gap Width & $34 \mathrm{~mm}$ \\
\hline Peak Current & $11.74 \mathrm{kA}$ \\
\hline Peak Power & $62 \mathrm{~kW}$ \\
\hline Pulse Width (1.5 kHz 1/2 sine wave) & $333 \mu \mathrm{s}$ \\
\hline Average Power & $0.042 \mathrm{~kW}$ \\
\hline
\end{tabular}

\subsection{Synchrotron AC Thick Extraction Septum}

This septum magnet is of the core-out-of-vacuum design, stacked to a radius of curvature of $30.5 \mathrm{~m}$, yielding a bending angle of $73.53 \mathrm{mrad}$. The core is composed of stacked laminations (4712) with laminated end packs that are chamfered at $45^{\circ}$. The core length is $1.7 \mathrm{~m}$.

The coils used in this magnet are fabricated from 4.19$\mathrm{mm}$ square conductor with a $2.41-\mathrm{mm}$ diameter hole for water cooling. The material is oxygen-free copper with CDA alloy no. 102. The coil configuration itself is a $6 \times 6$ matrix with dimensions of $2.86 \mathrm{~cm} \times 2.86 \mathrm{~cm}$ with a 4.19-cm gap. The coil is a saddle type, $1.76 \mathrm{~m}$ long, and weighs $15 \mathrm{~kg}$. This magnet is shown schematically in Fig. 4 with operational parameters given in Table 4 .

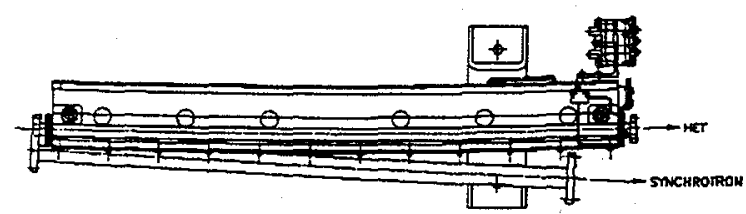

Figure 4: Top view synchrotron AC thick extraction septum 
Table 4: Synchrotron AC thick extraction septum and storage ring thick injection septum parameters

\begin{tabular}{|l|l|}
\hline Number & 1 \\
\hline Minimum Septum Thickness & $30 \mathrm{~mm}$ \\
\hline Physical Length & $1.79 \mathrm{~m}$ \\
\hline Effective Length & $1.75 \mathrm{~m}$ \\
\hline Bending Angle & $73.53 \mathrm{mrad}$ \\
\hline Peak Field at 7 GeV & $0.98 \mathrm{~T}$ \\
\hline Gap Height & $30 \mathrm{~mm}$ \\
\hline Gap Width & $40 \mathrm{~mm}$ \\
\hline Peak Current & $0.66 \mathrm{kA}$ \\
\hline Peak Power & $80 \mathrm{~kW}$ \\
\hline Pulse Width & $10 \mathrm{~ms}$ \\
\hline Average Power & $0.797 \mathrm{~kW}$ \\
\hline
\end{tabular}

\subsection{Storage Ring AC Thick Injection Septum}

The core and coils used for this magnet are identical to those used in the synchrotron AC thick extraction septum. The vacuum chamber used in this magnet is a curved rectangular chamber 1.535 inches high made from an Inconel $^{\circ}$ channel. The coils are the same as in the synchrotron $\mathrm{AC}$ thick extraction septum.

This magnet is shown schematically in Fig. 5 with operational parameters given in Table 4.

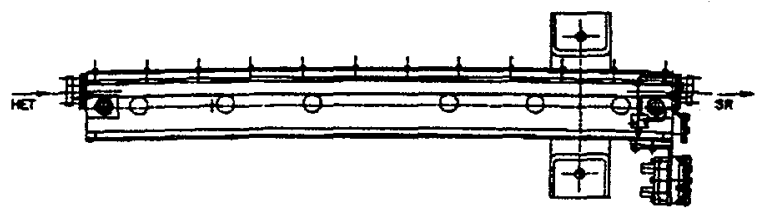

Figure 5: Storage ring AC thick injection septum

\subsection{Storage Ring AC Thin Injection Septum}

The core of the storage ring $\mathrm{AC}$ thin injection septum is comprised of $0.356-\mathrm{mm}$ thick laminations (M22 silicon steel with C5 coating) stacked to a length of $1.04 \mathrm{~m}$. On each end of the core are 2.52 -cm-thick laminated end packs. The core, which is stacked straight, is held together with side and bottom tie bars. Inside the gap is a formed beam vacuum tube. This tube is made from Inconcel 625 metal and is $127.8 \mathrm{~cm}$ long with a 0.347 $\mathrm{mm}$ wall thickness. It is positioned in the core by means of five tube supports fabricated from MYKROX/MYCALEX GRADE machinable ceramic. The copper septum conductor is $1.1 \mathrm{~mm}$ thick. Following assembly of the core, Inconel vacuum chamber, and ceramic stand-offs, the remaining open volume of the magnet gap is filled with a concrete type material thereby yielding a solid, one-piece unit suitable for high radiation environments. The magnet is then completed with the addition of the field-free tube vacuum chamber which doubles as a magnetic shield, tie bars, flanges, etc. The gap between the inside wall of the embedded vacuum chamber and the inside wall of the stored beam vacuum chamber is specified to be $2.4 \mathrm{~mm}$; however, in actuality it is $3.5 \mathrm{~mm}$. Special care is necessary in welding the vacuum chambers to prevent weld bead from enlarging this area. The septum magnet is shown in Fig. 6. Some operational parameters are given in Table 5.

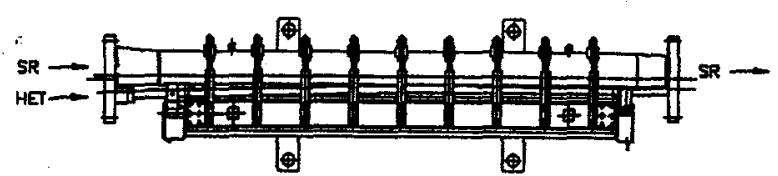

Figure 6: Top view of the storage ring $A C$ thin injection septum

Table 5: Storage ring AC thin injection septum parameters

\begin{tabular}{|l|l|}
\hline Number & 1 \\
\hline Maximum Effective Septum Thickness & $3.5 \mathrm{~mm}$ \\
\hline Physical Length & $1.06 \mathrm{~m}$ \\
\hline Effective Length & $1.05 \mathrm{~m}$ \\
\hline Gap Height & $20 \mathrm{~mm}$ \\
\hline Gap Width & $34 \mathrm{~mm}$ \\
\hline Bending Angle & $33 \mathrm{mrad}$ \\
\hline Peak Field & $0.73 \mathrm{~T}$ \\
\hline Peak Supply Current & $11.74 \mathrm{kA}$ \\
\hline Peak Power & $62 \mathrm{~kW}$ \\
\hline Power & $0.042 \mathrm{~kW}$ \\
\hline Pulse Width (1.5 kHz 1/2 sine) & $530 \mu \mathrm{s}$ \\
\hline Average Power & $0.042 \mathrm{~kW}$ \\
\hline
\end{tabular}

\section{CONCLUSION}

The primary septum effort at the APS is complete, and spare magnets have been assembled and tested. Existing magnets in the facility are being monitored for their performance, and maintence and upgrades are made as rquired. A new out-of-vacuum core direct-drive design for the synchrotron injection septum will soon be complete.

\section{ACKNOWLEDGMENTS}

The septum magnet program at APS has occupied the talents of many physicists, engineers, designers, and technicians. The author (AG) is at the end of a long effort that was a collaboration of many very capable people, listed below.

Physicists: Kenneth Thompson, Klaus Halbach, Fred Mills, Stephen Milton, John Galayda; Engineers: Stan Reeves, Sam Sheynin, James Humbert, Jack Jagger; Designers: Glen Cherry, Frank McConologue, Mike Harkins, Thomas Crain, Steven Hanuska, Ron Kmak; Technician: John Pace. 